\title{
Risk of cytomegalovirus infection and disease after umbilical cord blood transplantation in children
}

\author{
Pierre Alex Crisinel MD ${ }^{1}$, Michel Duval MD², Delphine Thuillard Crisinel ${ }^{1}$, Brigitte Mallette $\mathrm{PhD}^{3}$, Nathalie Bellier MD², \\ Marie-France Vachon MSn², Laurence Dedeken $\mathrm{MD}^{2}$, Céline Rousseau MD², Bruce Tapiero MD , Philippe Ovetchkine MD ${ }^{1}$
}

PA Crisinel, M Duval, D Thuillard Crisinel, et al. Risk of cytomegalovirus infection and disease after umbilical cord blood transplantation in children. Can J Infect Dis Med Microbiol 2013;24(1):e11-e15.

BACKGROUND: Pediatric data regarding cytomegalovirus (CMV) infections in pediatric patients receiving umbilical cord blood (UCB) transplantation are sparse.

OBJECTIVE: To determine whether UCB transplantation increases the risk of CMV infection and disease compared with other graft sources.

METHODS: The medical files of patients who underwent allogeneic hematopoietic stem cell transplantation at CHU Ste-Justine (Montreal, Quebec) from April 2000 to December 2006 were retrospectively reviewed. A Cox proportional hazard model was used to assess the effect of potential predictors of outcomes.

RESULTS: A total of 176 patients with a median age of nine years (range 0.1 to 18 years) underwent hematopoietic stem cell transplantation. The source of stem cells were UCB, bone marrow and peripheral blood stem cells in 86,86 and four of the cases, respectively. CMV infection occurred in 29 patients (16\%). At day 100 post-transplantation, the rate of CMV infection was $13 \%$ in UCB transplant recipients (11 of $86)$ versus $20 \%$ in those with other sources of graft ( 18 of 90$)(P=0.19)$. Positive CMV serology of the recipient and leukocyte depletion were two independent variables associated with an increased risk of CMV infection. Among infected patients, six developed CMV disease (20.7\%). The rate of CMV disease one year after infection was $49 \%$ in patients who received UCB (five of 11) and 6\% in others (one of 18). This difference was significant by univariate $(\mathrm{P}=0.01)$ but not by multivariate analysis.

CONCLUSION: In the setting of the current study, with a moderate CMV infection rate (16.5\%), UCB transplantation did not appear to increase the risk of CMV infection and disease.
Le risque d'infection et de maladie à cytomégalovirus après une greffe de sang du cordon ombilical chez les enfants

HISTORIQUE : Il existe peu de données pédiatriques sur les infections à cytomégalovirus (CMV) chez les patients pédiatriques qui reçoivent une greffe de sang du cordon ombilical (SCO).

OBJECTIF : Déterminer si la greffe de SCO accroît le risque d'infection à CMV par rapport à d'autres greffes.

MÉTHODOLOGIE : Les chercheurs ont procédé à une analyse rétrospective des dossiers médicaux de patients qui ont subi une greffe de cellules souches hématopoïétiques au CHU Sainte-Justine de Montréal, au Québec, entre avril 2000 et décembre 2006. Ils ont utilisé un modèle de risque proportionnel de Cox pour évaluer l'effet des prédicteurs potentiels d'issues.

RÉSULTATS : Au total, 176 patients ayant un âge médian de neuf ans (plage de 0,1 à 18 ans) ont subi une greffe de cellules souches hématopoïétiques. Les cellules souches provenaient du SCO, de la moelle épinière et du sang périphérique dans 86,86 et quatre cas, respectivement. Une infection à CMV s'est manifestée chez 29 patients (16\%). Au $100^{e}$ jour après la greffe, le taux d'infection à CMV s'élevait à $13 \%$ chez les greffés de SCO (11 sur 86 ) par rapport à $20 \%$ chez ceux dont la greffe provenait d'autres sources (18 sur 90$)(\mathrm{P}=0,19)$. La sérologie positive au CMV du receveur et la déplétion leucocytaire étaient deux variables indépendantes associées à un risque plus élevé d'infection à CMV. Chez les patients infectés, six ont contracté la maladie à CMV $(20,7 \%)$. Le taux de maladie à CMV un an après l'infection s'élevait à $49 \%$ chez les patients qui avaient reçu du SCO (cinq sur 11) et $6 \%$ chez les autres (un sur 18). Cette différence était significative selon l'analyse univariée ( $\mathrm{P}=0,01)$, mais pas selon l'analyse multivariée.

CONCLUSION : Dans le cadre de la présente étude, où le taux d'infection à CMV était modéré (16,5\%), la greffe de SCO ne semblait pas accroître le risque d'infection et de maladie à CMV.

Key Words: Children; Cytomegalovirus; Hematopoietic stem cell transplant; Umbilical cord blood

Cytomegalovirus (CMV) infection is a major problem in hemato$U_{\text {poietic stem cell transplantation (HSCT), due to both the direct }}$ effect of the virus and also the indirect impact on the graft, with the possibility of rejection or graft-versus-host disease (GVHD) (1). Prophylaxis or pre-emptive treatment is a preventive strategy that can successfully limit the high mortality and morbidity associated with CMV infections (2).

HSCT is presently a treatment of last resort for numerous malignant and nonmalignant diseases. As a source of stem cells, umbilical cord blood (UCB) increases the accessibility of grafting. The immaturity of these cells, while lowering the risk of developing GVHD, could increase the risk of infection due to lower immunity to certain microorganisms such as $\operatorname{CMV}(3,4)$. However, the results from the study by Barker et al (5) contradict this hypothesis and showed that UCB does not increase the risk of severe infections in children. The risk of CMV infection after UCB transplantation has been assessed in adults and compared with the risk of CMV infection after transplantation from other sources of stem cells. The results are conflicting: some report an increased risk (4), while others report a similar risk for CMV infection (6). There are currently no data on the risk of CMV infection and disease in purely pediatric populations transplanted with UCB. CHU Ste-Justine (Montreal, Quebec), a pediatric tertiary care centre, is increasingly using UCB for HSCT. The aim of the present study was to assess the risk of CMV infection and disease in a pediatric population transplanted with UCB compared with other sources of stem cells.

\footnotetext{
${ }^{1}$ Infectious Diseases Division; ${ }^{2}$ Onco-Hematology Division; ${ }^{3}$ Department of Microbiology and Immunology CHU Ste-Justine - Université de Montréal, Montréal, Québec

Correspondence: Dr Philippe Ovetchkine, 3175 ch de la Côte-Ste-Catherine, Montréal, Québec H3T 1C5. Telephone 514-345-4931,

fax 514-345-4908, e-mail philippe.ovetchkine@umontreal.ca
} 


\section{METHODS}

\section{Patients}

CHU Ste-Justine is the main pediatric HSCT centre in Quebec. All consecutive patients transplanted between April 2000 and December 2006 were identified in the computerized database of the HSCT program. Inclusion criteria were a first episode of allogeneic HSCT and $\leq 18$ years of age at the time of transplantation. Exclusion criteria were $>18$ years of age at the time of transplantation, a second episode of allogeneic HSCT and incomplete clinical data.

\section{Design}

The present analysis was a retrospective cohort study. The main objective was to assess the risk of CMV infection and disease in patients receiving an allogeneic HSCT as the source of stem cells. The primary end point was CMV infection and the secondary end point was CMV disease. The main evaluated risk factor was the type of graft and secondary risk factors included age, sex, diagnosis, CMV serostatus before HSCT, type of donor, conditioning regimen, type of prophylaxis against GVHD, leukocyte depletion, antiviral prophylaxis with acyclovir and the presence of GVHD. Data were collected on a standardized questionnaire from the medical files of patients. The same investigator compiled all of the data.

The present retrospective study was approved by the institutional review board of CHU Sainte-Justine.

\section{CMV surveillance and treatment}

At CHU Sainte-Justine, a pre-emptive strategy was adopted to prevent CMV disease. All transplanted patients are tested weekly for CMV viremia between 21 and 100 days post-transplantation, followed by testing on a monthly basis until the end of immunosuppressive treatment. The frequency and duration of CMV screening may vary depending on different parameters (immune reconstitution, previous CMV infection or disease). For patients who received antithymocyte globulins (ATG) before transplantation, CMV screening was initiated on the day of transplantation. The CMV screening technique used during the study period was the nucleic acid sequence-based assay (NASBA), which tests for the immediate-early messenger RNA of CMV, as previously described (7). A positive NASBA necessitates the introduction of specific antiviral treatment: ganciclovir at a dose of $10 \mathrm{mg} / \mathrm{kg} / \mathrm{day}$ in two divided doses until the completion of two consecutive negative NASBA tests. Treatment with foscarnet $(180 \mathrm{mg} / \mathrm{kg} /$ day divided into two doses on the first day followed by $90 \mathrm{mg} / \mathrm{kg} /$ day) was administered for cases in which there was no response or where there was a contraindication to ganciclovir (persistence of aplasia). In cases of suspected CMV disease, specific anti-CMV immune globulin was added to antiviral therapy.

All patients receiving an unrelated graft or who were $<2$ years of age, experienced hypogammaglobulinemia (immunoglobulin $G$ level $<5 \mathrm{~g} / \mathrm{L}$ ) or immune deficiency received a weekly intravenous infusion of standard immunoglobulin $(500 \mathrm{mg} / \mathrm{kg})$ starting three days before HSCT until 100 days following HSCT, which were continued monthly until the cessation of immunosuppressive treatment. Patients with positive herpes serology before HSCT received prophylaxis with intravenous acyclovir $\left(500 \mathrm{mg} / \mathrm{m}^{2} /\right.$ day in two divided doses) that started three days before HSCT and continued until 20 days post-HSCT. All administered blood products, with the exception of the graft, were irradiated and filtered ( $80 \mu \mathrm{m}$ filter).

\section{Definitions}

Infections, reinfections and CMV disease were defined according to the definitions published by Ljungman et al (8). Infection was defined by the detection of the virus and the absence of symptoms. Reinfection was defined as a second infection occurring after a gap of at least four weeks without evidence of the presence of the virus. CMV disease was considered to be present when there were clinical signs and evidence of organ damage (histological, molecular or viral). Patients who developed CMV disease before evidence of infection were considered infected and included as infection and disease cases in the statistical analyses.

\section{Statistical analyses}

A comparison of patient characteristics was performed using the $\chi^{2}$ test for categorical data and the Mann-Whitney U test or Student's $t$ test for continuous data. The cumulative incidence of infections and diseases was estimated by treating deaths unrelated to CMV as a competitive risk and censoring patients for nonengraftment and relapse. Univariate comparisons were made using the log-rank test. A Cox proportional hazard model was used to assess the effect of potential predictors of outcomes. All factors were tested according to a proportional hazard assumption $(9,10)$. SPSS version 13 (IBM Corporation, USA) for Windows (Microsoft Corporation, USA) was used for all analyses except the log-rank analysis (10), which was performed using R (R app GUI 1.25 [5166], S Urbanek \& SM lacus, The R Project for Statistical Computing, USA).

\section{RESULTS}

During the study period, 212 consecutive allogeneic HSCT were performed on 191 patients. Twenty-one episodes of a second HSCT were excluded, data were missing for five patients and 10 patients were $>18$ years of age. Therefore, 176 patients with a first episode of allogeneic HSCT were included in the analysis of risk factors for CMV infection and disease, as per the inclusion criteria. Eighty-six patients received an UCB HSCT while 90 received another source of graft; 86 received a bone marrow (BM) transplant and four received a peripheral blood stem cells (PBSC) transplant. Characteristics of the patients are summarized in Table 1.

The median age of patients was nine years (range 0.1 to 18 years). The ages of the children receiving the two different sources of stem cells were significantly different; children transplanted with UCB were younger (median age seven years, range 0.3 to 18 years) than those who received BM/PBSC transplants (median 10 years, range 0.1 to 18 years; $\mathrm{P}=0.035)$. Hematological malignancies represented the majority of indications for HSCT (122 of 176). Children with nonmalignant diseases (48 of 176) received BM/PBSC transplants preferentially (32 of 48), while children with cancer or hematological malignancies mainly received UCB transplants (70 of 128) ( $\mathrm{P}=0.04)$.

Other differences in characteristics according to the source of stem cells included the type of donor (related in 70 of 90 [77.7\%] BM/PBSC transplants versus $1.2 \%$ of $\mathrm{UCB}$ transplants; $\mathrm{P}<0.001$ ) and in the CMV serological profile. Forty-five recipients $(25.6 \%)$ had a positive CMV serology before HSCT. Seronegativity was found for both recipient and donor (R-/D-) among 67\% of patients (118 of 176), while seropositivity in the recipient and seronegativity in the donor $\left(\mathrm{R}+/ \mathrm{D}^{-}\right)$ was present among $15.9 \%$ of patients (28 of 176), including 19 children receiving UCB (22.1\% versus $10 \%$ in the BM/PBSC group; $\mathrm{P}<0.001)$. A myeloablative conditioning regimen was used for 161 of 176 HSCTs (91.5\%); $97.7 \%$ of UCB HSCT cases (84 of 86 ) versus $85.6 \%$ of HSCT cases with another source of stem cells (77 of 90) $(\mathrm{P}=0.004)$. Methotrexate and cyclosporine were used for $92.2 \%$ of patients with BM/PBSC HSCT (83 of 90) for prophylaxis against GVHD and for $18.6 \%$ of patients who received UCB HSCT (16 of 86; $\mathrm{P}<0.001)$. Leukocyte depletion was mainly effected through in vivo administration of ATG for children with UCB HSCT (83 of 90 [96.5\%], with only one case of ex vivo depletion), while $54.4 \%$ of children with BM/PBSC HSCT (49 of 90) did not undergo either ex vivo or in vivo leukocyte depletion $(\mathrm{P}<0.001)$. The median follow-up period of surviving patients was 31 months (range one to 87 months) with no significant differences between sources of stem cells.

\section{Incidence of CMV infection}

Among the 176 patients, 29 (16.5\%) developed CMV infection after a median period of 33 days (range zero to 68 days) following HSCT. At day 100 post-HSCT, the rate of CMV infection was $13 \%$ for UCB transplant recipients ( 11 of 86 ) versus $20 \%$ for other sources of stem cells (18 to 90) 
TABLE 1

Baseline characteristics of patients

\begin{tabular}{|c|c|c|c|c|}
\hline Factor & BM/PBSC & UCB & Total & $\mathbf{P}$ \\
\hline Source of stem cells & $90(51.1)$ & $86(48.9)$ & $176(100)$ & \\
\hline \multicolumn{5}{|l|}{ Age at transplant, years } \\
\hline$\leq 9$ & 39 (43.3) & $49(57)$ & $88(50)$ & 0.07 \\
\hline$>9$ & $51(56.7)$ & $37(43)$ & $88(50)$ & \\
\hline Median (range) & $10(0.1-18)$ & $7(0.3-18)$ & $9(0.1-18)$ & 0.035 \\
\hline \multicolumn{5}{|l|}{ Recipient sex } \\
\hline Female & $41(45.6)$ & $33(38.4)$ & $74(42)$ & 0.34 \\
\hline Initial diagnosis & & & & 0.04 \\
\hline Nonmalignancy* & $32(35.6)$ & $16(18.6)$ & $48(27.3)$ & \\
\hline $\begin{array}{l}\text { Hematological } \\
\text { malignancy }^{\dagger}\end{array}$ & $55(61.1)$ & 67 (77.9) & $122(69.3)$ & \\
\hline Other malignancy ${ }^{\ddagger}$ & $3(3.3)$ & $3(3.5)$ & $6(3.4)$ & \\
\hline Donor type & & & & $<0.001$ \\
\hline Unrelated donor & $20(22.2)$ & 85 (98.8) & $105(59.7)$ & \\
\hline Related donor & $70(77.8)$ & $1(1.2)$ & $71(40.3)$ & \\
\hline CMV serology & & & & $<0.001$ \\
\hline $\mathrm{R}-/ \mathrm{D}-$ & $53(58.9)$ & $65(75.6)$ & $118(67)$ & \\
\hline $\mathrm{R}-/ \mathrm{D}+$ & $11(12.2)$ & $2(2.3)$ & $13(7.4)$ & \\
\hline $\mathrm{R}+/ \mathrm{D}-$ & $9(10)$ & $19(22.1)$ & $28(15.9)$ & \\
\hline $\mathrm{R}+/ \mathrm{D}+$ & $17(18.9)$ & $0(0)$ & $17(9.7)$ & \\
\hline CMV recipient serology & & & & 0.3 \\
\hline Negative & $64(71.1)$ & $67(77.9)$ & $131(74.4)$ & \\
\hline Positive & $26(28.9)$ & $19(22.1)$ & $45(25.6)$ & \\
\hline Conditioning regimen & & & & 0.004 \\
\hline Myeloablative & 77 (85.6) & $84(97.7)$ & 161 (91.5) & \\
\hline Nonmyeloablative & $13(14.4)$ & $2(2.3)$ & $13(7.4)$ & \\
\hline GVHD prophylaxis & & & & $<0.001$ \\
\hline Methotrexate/CsA & $83(92.2)$ & $16(18.6)$ & 99 (56.2) & \\
\hline CsA/MMF & $0(0)$ & $2(2.3)$ & $2(1.1)$ & \\
\hline CsA/Prednisone & $0(0)$ & 67 (77.9) & 67 (38.1) & \\
\hline None & $4(4.4)$ & $1(1.2)$ & $5(2.8)$ & \\
\hline Other & $3(3.3)$ & $0(0)$ & $3(1.7)$ & \\
\hline Antiviral prophylaxis & & & & 0.5 \\
\hline None & $30(33.3)$ & $33(38.4)$ & $63(56)$ & \\
\hline Acyclovir & $60(66.7)$ & $53(61.6)$ & $113(42)$ & \\
\hline Leukocyte depletion & & & & $<0.001$ \\
\hline Ex vivo & $3(3.3)$ & $1(1.2)$ & $4(2.3)$ & \\
\hline In vivo (ATG) & 38 (42.2) & $83(96.5)$ & 121 (68.8) & \\
\hline None & $49(54.4)$ & $2(2.3)$ & $51(29)$ & \\
\hline
\end{tabular}

Data presented as $n$ (\%) unless otherwsise indicated. ${ }^{*}$ Nonmalignancies included aplastic anemia, immune deficiency, sickle cell disease and storage disorders; ${ }^{\dagger}$ Hematological malignancies included acute lymphocytic leukemia, acute myelogenous leukemia and myelodysplastic syndrome; ${ }^{\ddagger}$ Other malignancies included non-Hodgkin's lymphoma, Hodgkin's lymphoma and neuroblastoma. ATG Antithymocyte globulin; BM Bone marrow; CMV Cytomegalovirus; CSA Cyclosporine A; D Donor; GVHD Graft-versus-host disease; MMF Mycophenolate mofetil; PBSC Peripheral blood stem cells; $R$ Recipient; UCB Umbilical cord blood transplant; - Negative serology; + Positive serology

(Figure 1). This difference was not statistically significant $(\mathrm{P}=0.19)$. There was no CMV infection among PBSC transplant recipients.

Positive CMV serology of the recipient $(\mathrm{P}<0.001)$, and leukocyte depletion $(\mathrm{P}=0.03)$ were the only variables significantly associated with an increased rate of CMV infection. For CMV seronegative recipients, the serological status of the donor determined the rate of CMV infection; $15 \%$ in the case of positive donors (two of 13 ) and 1\% for negative donors (one of 118). Positive CMV serology of the recipient was associated with an incidence of infection of $48 \%$ (22 of 45; [95\% CI $43 \%$ to $73 \%$ ]) compared with an incidence of $2 \%$ (three of

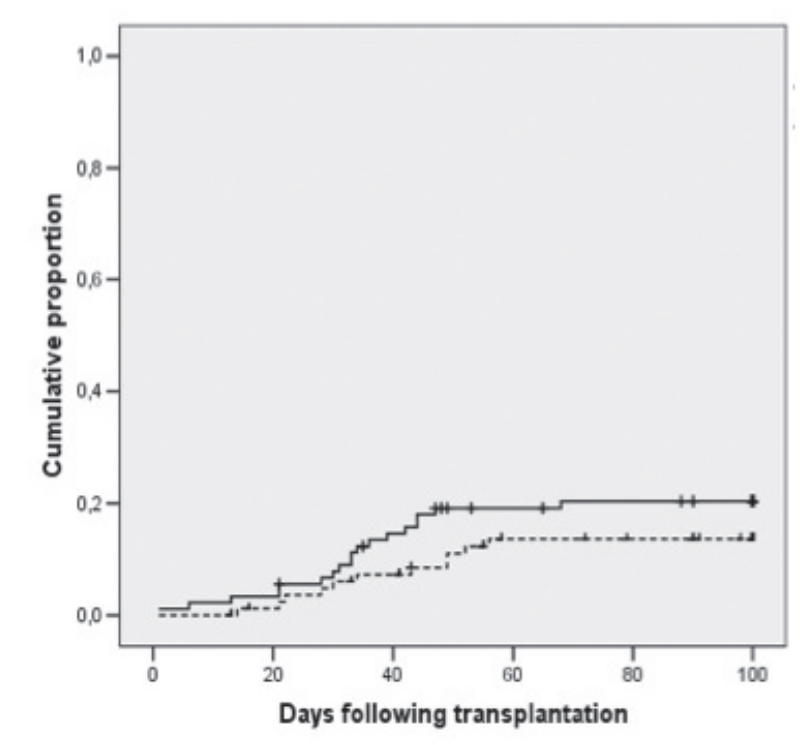

Figure 1) Cumulative proportion of cytomegalovirus infection 100 days post-hematopoietic stem cell transplantation. Bone marrow and peripheral blood stem cells (solid line) was 20\% (95\% CI 12\% to 28\%). Umbilical cord blood (dashed line) was 13\% (95\% CI 6\% to 20\%). (P=0.19 using univariate analysis)

131; [95\% CI $0 \%$ to 5\%]) for negative CMV serology. CMV was detected among $20 \%$ (95\% CI $13 \%$ to $27 \%$ ) of cases having experienced leukocyte depletion ( 25 of 125 ) and $8 \%$ of cases without depletion (four of 51).

The other variables (age, sex, initial diagnosis, source of stem cells, conditioning regimen, GVHD prophylaxis, prophylaxis with acyclovir, GVHD) did not appear to be risk factors for CMV infection using univariate analysis. Using multivariate analysis, positive CMV serology of the recipient (RR 67.2 [95\% CI 17 to 265.8]) and leukocyte depletion (RR 4.8 [95\% CI 1.2 to 19.9]) were independent factors associated with increased risk of CMV infection (Table 2).

Incidence of CMV disease among infected patients

Among the 29 infected patients, six developed CMV disease (20.7\%). The proportion of patients experiencing CMV disease after CMV infection was $45 \%$ among UCB HSCT recipients (five of 11 ) and $6 \%$ among BM HSCT recipients (one of 18). All five UCB HSCT recipients were treated with ATG and had a R+/D- CMV serological profile, while the only BM HSCT recipient did not receive ATG and had a $\mathrm{R}-/ \mathrm{D}-\mathrm{CMV}$ serological profile. The difference in proportion of CMV disease was significant by univariate analysis $(P=0.01)$. The median time to onset of CMV disease was 64.5 days (range two to 340 days). Other factors associated with an increased incidence of CMV disease were female sex $(\mathrm{P}=0.009)$, serological profile $(\mathrm{P}=0.001)$ and type of prophylaxis against GVHD $(\mathrm{P}=0.04)$. However, none of these factors appeared to be a risk factor by multivariate analysis. The patient with BM HSCT developed colitis. Among the five patients with UCB HSCT, three had one organ involved (two patients with pneumonia, one patient with retinitis) and two experienced multisystem damage (one patient with retinitis and pneumonia and one child with encephalitis, colitis and retinitis). Two patients with UCB HSCT died. One of these deaths was directly related to CMV disease (pneumonitis).

\section{DISCUSSION}

The present study was one of a limited number of pediatric studies assessing the risk of CMV infection and disease after UCB transplantation. CMV has long been recognized as a serious threat in the first months after HSCT (1), but knowledge concerning CMV infections and disease in pediatric HSCT has been extrapolated mainly from 


\begin{tabular}{|c|c|c|}
\hline Factor & RR $(95 \% \mathrm{Cl})$ & $\mathbf{P}$ \\
\hline \multicolumn{3}{|l|}{ Recipient sex } \\
\hline Female & $0.7(0.3-1.7)$ & 0.38 \\
\hline \multicolumn{3}{|l|}{ Age, years } \\
\hline$\leq 9$ & 1 & \\
\hline$>9$ & $1(0.4-2.5)$ & 0.94 \\
\hline Positive CMV recipient serology & $67.2(17-265.8)$ & $<0.001$ \\
\hline Umbilical cord blood graft source & $0.1(0.01-1.6)$ & 0.12 \\
\hline \multicolumn{3}{|l|}{ Graft-versus-host disease prophylaxis } \\
\hline Cyclosporine A/methotrexate & 1 & \\
\hline Cyclosporine A/prednisone & $2.8(0.2-32.8)$ & 0.42 \\
\hline T cell depletion (including ATG) & $4.8(1.2-19.9)$ & 0.03 \\
\hline Acyclovir prophylaxis & $0.6(0.2-1.7)$ & 0.38 \\
\hline Acute graft-versus-host disease & $2.5(0.8-7.3)$ & 0.1 \\
\hline Myeloablative conditioning regimen & $1.6(0.3-7.9)$ & 0.53 \\
\hline \multicolumn{3}{|l|}{ Initial diagnosis } \\
\hline Nonmalignant diseases* & 1 & \\
\hline Hematological and other malignancies ${ }^{\dagger}$ & $1.5(0.5-4.4)$ & 0.44 \\
\hline \multicolumn{3}{|l|}{ Donor type } \\
\hline Related donor & 1 & \\
\hline Unrelated donor & $0.5(0.1-2.4)$ & 0.4 \\
\hline
\end{tabular}

*Nonmalignant diseases included aplastic anemia, immune deficiency, sickle cell disease and storage disorders; ${ }^{\dagger}$ Hematological and other malignancies included acute lymphocytic leukemia, acute myelogenous leukemia and myelodysplasic syndrome, non-Hodgkin's lymphoma, Hodgkin's lymphoma and neuroblastoma. ATG Antithymocyte globulins

studies involving adults. The few existing pediatric data showed the incidence of CMV infection ranged from $11 \%$ to $40 \%$. Factors associated with an increased incidence of CMV infection were positive CMV serology status of the recipient (11-15), an unrelated donor (1115), leukocyte depletion (13-15), and the presence of high-grade GVHD (14) or treatment by steroids for acute GVHD (15). These pediatric studies have been conducted in settings where UCB transplantation was not used or only marginally used. However, in one of these studies (15), 16 of 117 pediatric patients received a UCB transplant. Eight of these patients (50\%) developed a CMV infection compared with 20 (20\%) from other graft sources, but this difference did not appear to be statistically significant. Incidence of CMV disease was $5.9 \%$ (seven of 117 ), but there were no details on the source of stem cells among the seven patients experiencing CMV disease.

Studies assessing the risk of CMV infection among adult UCB HSCT recipients had conflicting conclusions. Matsumura et al (16) reported a rate of $55 \%$ of CMV infection in a population of 140 adults after UCB transplantation. Risk factors for CMV infection included a high number of CD34 cells in the transplant and the presence of GVHD. However, the patients' CMV serological status was unknown and there were no controls. Takami et al (17) compared the rate of CMV infection in 10 recipients positive for CMV serology after UCB HSCT and 74 recipients positive for CMV serology after BM HSCT. They reported that all patients transplanted with UCB developed a CMV infection versus $55 \%$ of patients who received a BM transplant. Of note, all patients receiving UCB HSCT had an R+/D- CMV serological profile versus only $8 \%$ of the patients who received BM HSCT (17). Tomonari et al (18) reported a rate of $76 \%$ of CMV infection in 28 adults receiving UCB HSCT versus $66 \%$ in 49 patients receiving BM HSCT; however, this difference was not statistically significant. As part of a study on the risk of severe infections in transplanted adults, Parody et al (4) showed that the risk of CMV infection was statistically higher when the patients received UCB HSCT (85\%) rather than an HSCT from another source of stem cells (69\%), without any impact on disease incidence or mortality related to infection.
More recently, Walker et al (6) contributed to the knowledge regarding the risk of CMV infection among patients receiving UCB HSCT. The authors reported the results of a retrospective study of a large population involving 753 patients (adults and children) receiving allogeneic HSCT and showed that the rate of CMV infection and disease observed six months after HSCT was not significantly different between the group of patients who received UCB compared with the group who received stem cells from other sources. Risk factors associated with CMV infection were positive CMV serology before transplantation, the presence of GVHD and leukocyte depletion. It is interesting to note that $44 \%$ of this population was $<18$ years of age, which may explain the lower incidence of infections (22\%) than what is usually reported in adult studies. Indeed, in this population, $>50 \%$ of the recipients had positive CMV serology, a proportion lower than that what has been observed in other adult studies, where the rate of patients with positive CMV serology is often $>75 \%$. This may explain the higher incidence of CMV infection, $>55 \%$ of patients, for all sources of stem cells combined.

This suggests that UCB, as a source of stem cells, could influence the risk of CMV infection differently according to whether one is in a population with low or high seroprevalence for CMV. The increased risk of CMV infection described by Parody et al (4) in a population with high CMV seroprevalence could be enhanced by UCB transplantation, namely, an immature immune system with a lack of specific CMV immunity and delayed immune reconstitution. These harmful elements may not have the same influence in a population with low CMV seroprevalence. In our pediatric study, the rate of recipients with positive CMV serology was low (25.6\%) leading to a moderate rate of infection (16.5\%).

Our results highlight the importance of positive CMV serology as well as leukocyte depletion in transplant recipients. GVHD was not associated with an increased risk of infection; however, it should be noted that we did not distinguish low-grade GVHD (I) from GVHD of moderate to severe grade (II-IV).

The present study, conducted in an entirely pediatric population, confirms the results of Walker et al (6) that the risk of CMV infection is not associated with UCB HSCT. In our study, we used a sensitive CMV screening method (NASBA) instead of CMV antigenemia as was often used in previous studies. Some authors have reported NASBA to be a more sensitive screening method compared with antigenemia (19), enabling detection of CMV infection earlier and leading to the administration of specific antiviral treatment more promptly. This could partially explain the lower rate of CMV disease (3.4\%) observed in our study compared with that reported by Walker et al (6) (6\% to 9\%).

CMV disease occurred mainly in UCB recipients (five of six) rather than in patients receiving stem cells from other sources. However, this statistically significant difference using univariate analysis was no longer present using multivariate analysis, probably due to the small number of cases, but suggests that CMV infection occurring in UCB patients could lead more easily to CMV disease, despite sensitive screening and prompt initiation of therapy.

The retrospective design of the present study limits the conclusions that can be drawn. Differences in the nature of the sources of stem cells lead to differences in baseline characteristics that could introduce bias that is difficult to control. However, our robust statistical analyses support the reliability of the results. The hypothesis of a potentially higher risk of CMV infection among UCB transplants may be rejected in a population with low CMV seroprevalence. Other studies in populations with higher CMV seroprevalence are desirable not only to clarify the role of UCB in the occurrence of CMV infection but also to elucidate the association between UCB transplantation and CMV disease that our results suggest without formally demonstrating.

\section{REFERENCES}

1. Boeckh M, Nichols WG. The impact of cytomegalovirus serostatus of donor and recipient before hematopoietic stem cell transplantation in the era of antiviral prophylaxis and preemptive therapy. Blood 2004;103:2003-8. 
2. Bueno J, Ramil C, Green M. Current management strategies for the prevention and treatment of cytomegalovirus infection in pediatric transplant recipients. Paediatr Drugs 2002;4:279-90.

3. Brown JA, Boussiotis VA. Umbilical cord blood transplantation: Basic biology and clinical challenges to immune reconstitution. Clin Immunol 2008;127:286-97.

4. Parody R, Martino R, Rovira M, et al. Severe infections after unrelated donor allogeneic hematopoietic stem cell transplantation in adults: Comparison of cord blood transplantation with peripheral blood and bone marrow transplantation.

Biol Blood Marrow Transplant 2006;12:734-48.

5. Barker JN, Hough RE, van Burik JA, et al. Serious infections after unrelated donor transplantation in 136 children: Impact of stem cell source. Biol Blood Marrow Transplant 2005;11:362-70.

6. Walker CM, van Burik JA, De For TE, Weisdorf DJ. Cytomegalovirus infection after allogeneic transplantation: Comparison of cord blood with peripheral blood and marrow graft sources. Biol Blood Marrow Transplant 2007;13:1106-15.

7. Gerna G, Lilleri D. Monitoring transplant patients for human cytomegalovirus: Diagnostic update. Herpes 2006;13:4-11.

8. Ljungman P, Griffiths P, Paya C. Definitions of cytomegalovirus infection and disease in transplant recipients. Clin Infect Dis 2002;34:1094-7.

9. Lin DY. Non-parametric inference for cumulative incidence functions in competing risks studies. Stat Med 1997;16:901-10.

10. Scrucca L, Santucci A and Aversa F. Competing risk analysis using R: An easy guide for clinicians. Bone Marrow Transplant 2007;40:381-7.

11. Haastrup E, Muller K, Baekgaard H, Heilmann C. Cytomegalovirus infection after allogeneic stem cell transplant in children. Pediatr Transplant 2005;9:734-40

12. Bordon V, Bravo S, Van Renterghem L, et al. Surveillance of cytomegalovirus (CMV) DNAemia in pediatric allogeneic stem cell transplantation: Incidence and outcome of CMV infection and disease. Transpl Infect Dis 2008;10:19-23.

13. Patel SR, Ridwan RU, Ortin M. Cytomegalovirus reactivation in pediatric hemopoietic progenitors transplant: A retrospective study on the risk factors and the efficacy of treatment. J Pediatr Hematol Oncol 2005;27:411-5.

14. Matthes-Martin S, Lion T, Aberle SW, et al. Pre-emptive treatment of CMV DNAemia in paediatric stem cell transplantation: The impact of recipient and donor CMV serostatus on the incidence of CMV disease and CMV-related mortality. Bone Marrow Transplant 2003;31:803-8.

15. Yoon HS, Lee JH, Choi ES, et al. Cytomegalovirus infection in children who underwent hematopoietic stem cell transplantation at a single center: A retrospective study of the risk factors. Pediatr Transplant 2009;13:898-905.

16. Matsumura T, Narimatsu H, Kami M, et al. Cytomegalovirus infections following umbilical cord blood transplantation using reduced intensity conditioning regimens for adult patients. Biol Blood Marrow Transplant 2007;13:577-83.

17. Takami A, Mochizuki K, Asakura H, Yamazaki H, Okumura H, Nakao S. High incidence of cytomegalovirus reactivation in adult recipients of an unrelated cord blood transplant. Haematologica 2005;90:1290-2.

18. Tomonari A, Iseki T, Ooi J, et al. Cytomegalovirus infection following unrelated cord blood transplantation for adult patients: A single institute experience in Japan. Br J Haematol 2003;121:304-11.

19. Gerna G, Lilleri D, Baldanti F, et al. Human cytomegalovirus immediate-early mRNAemia versus pp65 antigenemia for guiding pre-emptive therapy in children and young adults undergoing hematopoietic stem cell transplantation: A prospective, randomized, open-label trial. Blood 2003;101:5053-60. 


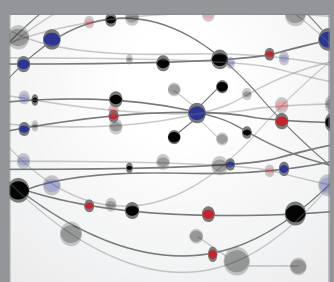

The Scientific World Journal
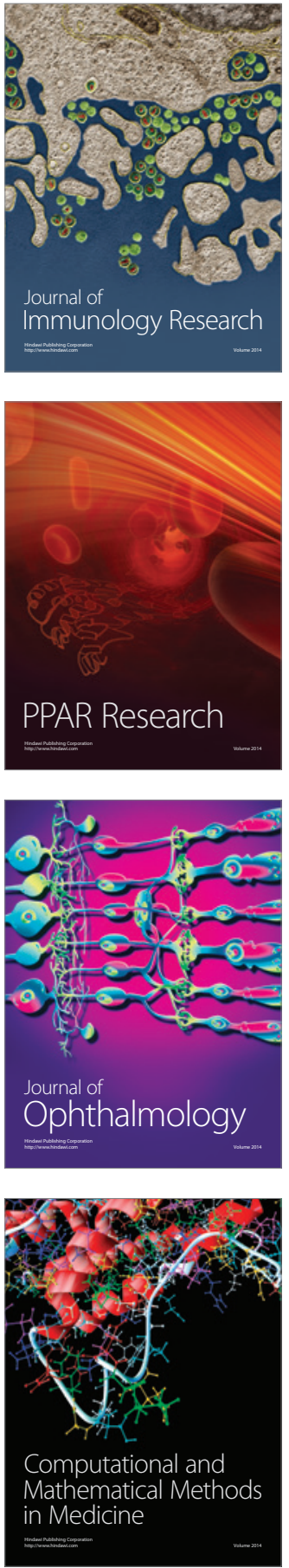

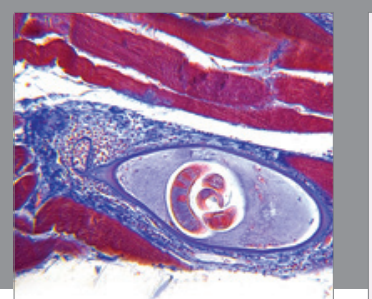

Gastroenterology Research and Practice

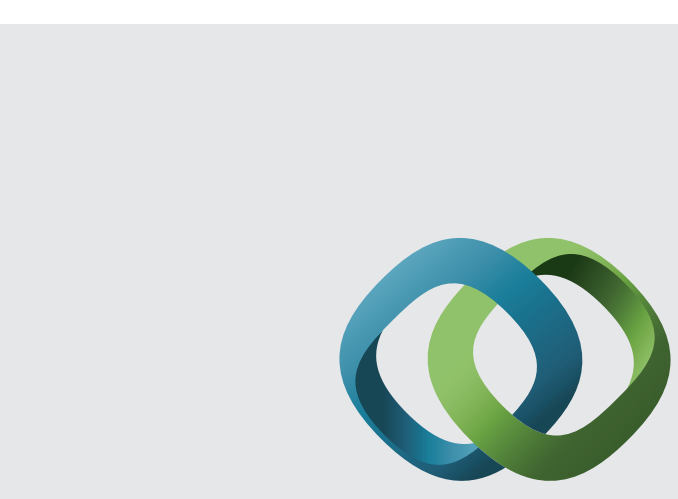

\section{Hindawi}

Submit your manuscripts at

http://www.hindawi.com
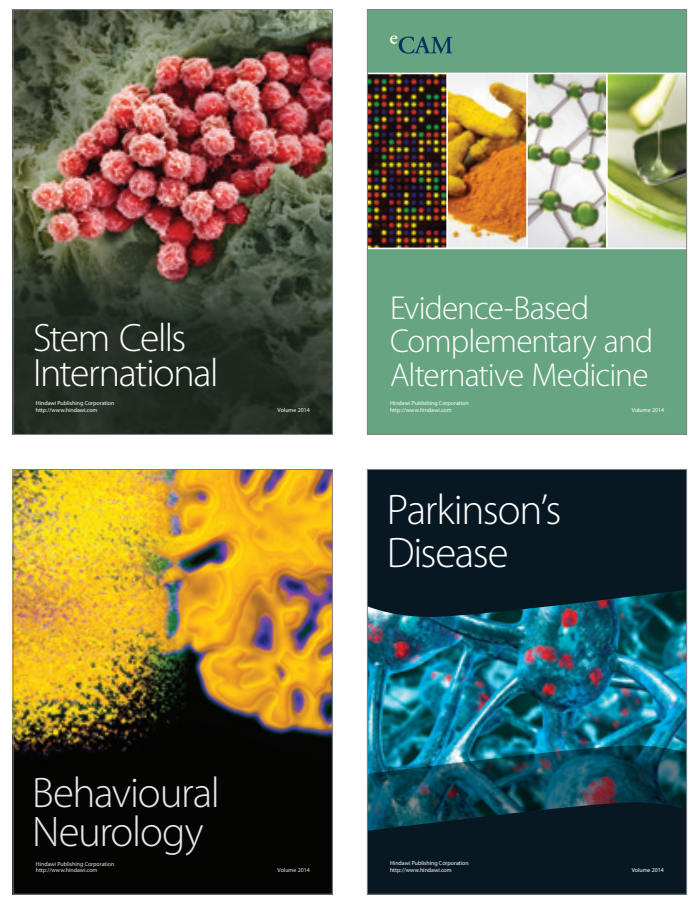
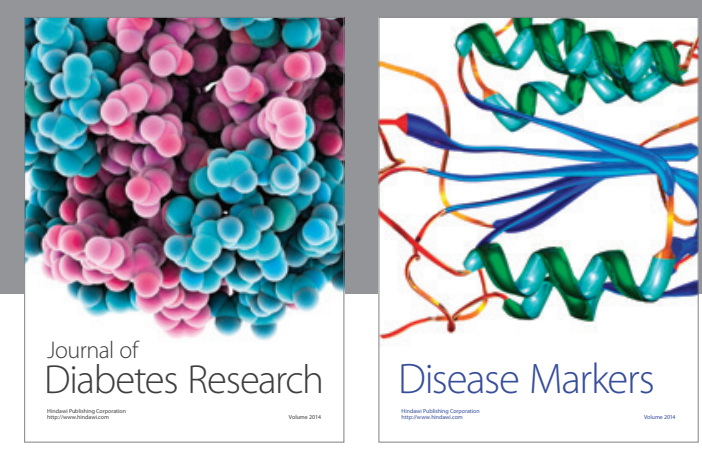

Disease Markers
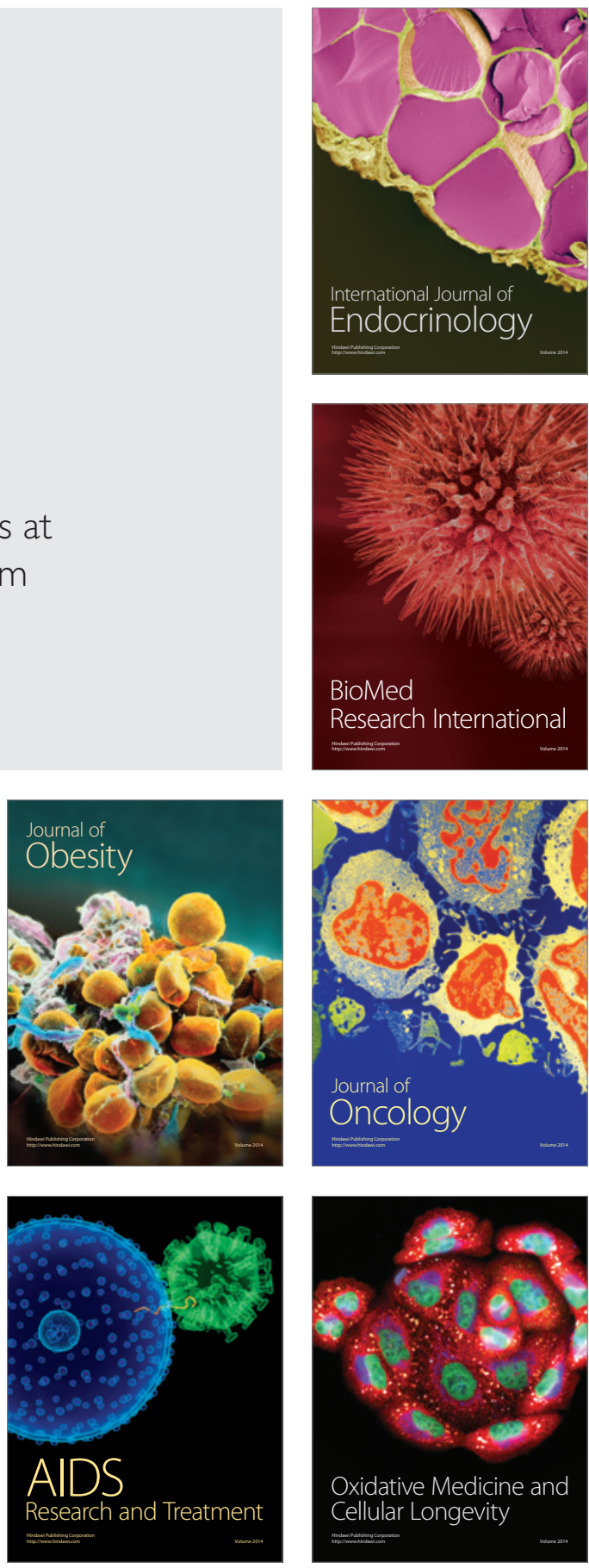